\title{
Tradições de matriz africana e sexo: reflexões afroteológicas ${ }^{1}$
}

\author{
(African matrix traditions and sex: afroteological reflections)
}

ISSN: 2358-0844

ก. 14 . v. I nov.2020-abr.2021 р. 73-90.
(Tradiciones de la matriz africana y sexo: reflexiones afroteológicas)

RESUMO: Este artigo é resultado de nossa pesquisa no doutorado que apresenta questões pouco tratadas na literatura acadêmica a respeito do sexo nas tradições de matriz africana como o Batuque e o Candomblé. Oferecemos uma análise afroteológica do ritual de Borí no Batuque; analisamos certos aspectos dos Òị̀à e ofereceremos uma interpretação afroteológica do tema; trataremos das relações interpessoais como atos sexuais e relações românticas entre os vivenciadores e tratamos brevemente de elementos da sexualidade e identidade de gênero. Como método, utilizamos a exunêutica.

PALAVRAS-CHAVE: Afroteologia. Sexo. Sexualidades. Borí. Relações românticas.

\begin{abstract}
This paper is the result of our research in the doctorate that presents questions little dealt with in the academic literature about sex in traditions of African origin such as Batuque and Candomblé. We offer an afrotheological analysis of the Borí in Batuque ritual; we analyze certain aspects of Orisha and offer an afrotheological interpretation to the theme; we will deal with interpersonal relationships as sexual acts and romantic relationships between the experiencers and we will briefly deal with elements of sexuality and gender identity. As a method we use eshuneutics.
\end{abstract}

Keywords: Afrotheology. Sex. Sexualities. Borí. Romantic relationships.

Resumen: Este artículo es el resultado de nuestra investigación en el doctorado que presenta preguntas poco tratadas en la literatura académica sobre sexo en tradiciones africanas como Batuque y Candomblé. Ofrecemos un análisis afroteológico del ritual Borí no Batuque; analizamos ciertos aspectos de Orisha y ofrecemos una interpretación afroteológica al tema; trataremos las relaciones interpersonales como actos sexuales y relaciones románticas entre los experimentadores y trataremos brevemente los elementos de la sexualidad y la identidad de género. Como método usamos eshunêutica.

Palabras clave: Afroteología. Sexo. Sexualidades. Borí. Relaciones románticas.

\footnotetext{
${ }^{1}$ Este artigo é uma versão adaptada de parte de um dos capítulos da tese de doutorado intitulada Afroteologia: construindo uma teologia das tradições de matriz africana, defendida no programa de pós-graduação em Teologia das Faculdades EST, em 2019, sob a orientação do Prof. Dr. Oneide Bobsin

${ }^{2}$ Doutor e Mestre em Teologia pelas Faculdades EST. Especialista em Ciências da Religião (Ucam). Graduado em História (Fapa). Criador e docente do curso de extensão universitáría em Teologia das Tradições de Matriz Africana da ESTEF. Assessor Técnico do Conselho do Povo de Terreiro do Estado do Rio Grande do Sul. Membro do grupo de pesquisa Identidade Étnica e Interculturalidade (EST). Bàbálórișà da Comunidade Tradicional de Terreiro Ilé Àṣe Òrị̣à Wúre. E-mail: hendrixsilveira@yahoo.com.br
} 


\section{Introdução}

As tradições de matriz africana sempre foram e são muito estudadas e debatidas sob vários aspectos por pesquisadores da antropologia, história, sociologia, filosofia, psicologia, geografia, ciências da religião e teologia, mas não há qualquer estudo sobre aspectos mais íntimos, como as relações românticas e sexuais, que dela também emergem.

De certa forma, as relações românticas e sexuais são tratadas como tabu entre os afrorreligiosos e mesmo entre os pesquisadores, mas nos parece que isto se dá pela colonialidade ao qual estas tradições estão expostas. Uma colonialidade profundamente cristianocentrada.

No início de 2016 começamos a estudar o livro Sexo \& religião, do cientista da religião norueguês Dag Øistein Endsjø (2014). Ele escreve um livro ousado sobre a relação entre dois temas polêmicos, a obra faz comparações entre diferentes religiões e como elas interpretam a questão da sexualidade desde seus primórdios até os dias de hoje.

Endsjø se apresenta bem crítico às contradições e suas conclusões e ao final de cada capítulo expõe as falhas nas doutrinas religiosas sobre a questão. Sua pesquisa se deu pela análise de textos sagrados e das doutrinas ensinadas por diferentes e importantes figuras religiosas ao longo da história, inclusive as interpretações distorcidas destes textos.

No ano seguinte, recebemos convite para publicação de um artigo na revista do programa de pós-graduação em relações étnicas e contemporaneidade da UESB - Universidade Estadual do Sudoeste da Bahia - cujo dossiê temático seria: "O Erótico e o Sagrado: Religiões de Matriz Africana"3. Infelizmente não havia tempo hábil para a produção de um artigo, mas fomos instigados a produzi-lo e o resultado é este que vos apresento.

A partir da obra de Endsjø e nossa vivência na tradição afrodiaspórica denominada Batuque, desenvolvemos um tema que imbrique Teologia e sexo. Não propomos aqui uma Afroteologia da Sexualidade, mas uma reflexão afroteológica e afrofilosófica sobre os ritos e as relações românticas e sexuais que acontecem dentro e fora das comunidades tradicionais de terreiro.

\footnotetext{
${ }^{3} \mathrm{O}$ dossiê, por motivos que desconhecemos, não foi publicado com este tema, mas sim Legados Africanos $e$ Experiências do Sagrado e incluiu artigos com a temática anterior. 
Como referencial teórico-metodológico nos valemos da abordagem afrocentrada cuja perspectiva "incorpora progressivamente [...] obras elaboradas na tradição ocidental [à] ética e filosofia ancestrais e a produção de conhecimento por africanos no seu próprio contexto de vida, antes e/ou independentemente do domínio colonial e escravista mercantil”. (FINCH III; NASCIMENTO, 2009, p. 41)

Consideramos em nossos trabalhos o termo 'tradições de matriz africana' como uma categoria que melhor define as diversas tradições vivenciadas nos terreiros das Américas e da África. Preferimos o termo 'tradições' a 'religiões', por entendermos que este último não contempla toda a complexidade civilizatória africana que ultrapassa os limites semânticos que a palavra carrega, e a usamos no plural, por entendermos que se exprimem numa diversidade de fenômenos. O termo 'matriz', grafado no singular, é utilizado por entendemos que há apenas uma matriz teológica e filosófica, assim como há uma unidade na diversidade da própria África enquanto continente que agrega mais de oitocentos grupos étnicos ${ }^{4}$. Esta unidade estaria vinculada a organizadores civilizatórios invariantes, tais como "tradição oral, sistema oracular divinatório, culto e manifestação de divindades, ritos de iniciação e de passagem", que servem para forjar um paradigma civilizatório negro-africano. (ALVES, 2012, p. 56) Ou, como diz o teólogo espanhol, radicado em Angola, Raul Ruiz de Asúa Altuna:

Embora as manifestações desta Religião Tradicional e algumas crenças variem de uma zona a outra e até de um grupo a outro, se pode falar com exatidão de "Religião Tradicional Africana". A unidade de crenças, o substrato fundamental, o significado e a finalidade dos cultos, ritos e símbolos e a homogeneidade de aspirações mostram-se idênticos em toda a África Negra. Os seus traços essenciais são comuns e os acidentes não rompem a unidade básica. (ALTUNA, 1985, p. 369)

Exunêutica (SILVEIRA, 2012) foi o método que se apresentou a nós no transcurso de nosso mestrado e doutorado e se constitui, principalmente, em interpretar o mundo a partir da cosmopercepção (OYĚWÙMÍ, 1997) que aflora na experiência vivida no terreiro. O termo é derivado de hermenêutica que, segundo Grondin (1999, p. 23), é “a ciência e, respectivamente, a arte da interpretação". Interpretar os dados que nos apresentaram foi um trabalho que necessitou de um olhar mais específico. 
Temos compreendido que a vivência em comunidades tradicionais de terreiro propõe uma interpretação do mundo calcada nos valores civilizatórios africanos, como a hermenêutica da vida apontada pelo filósofo alemão Wilhelm Dilthey (1992). Logo, imaginamos que se a hermenêutica é um termo originado no culto ao deus grego da comunicação e interpretação Hermes, o termo que sintetiza a forma afrocentrada de interpretação é a exunêutica, a divindade yorùbá da comunicação e interpretação: Èșù ${ }^{5}$.

Dividimos o tema da pesquisa em quatro subtítulos, sendo que no primeiro oferecemos uma análise afroteológica do ritual de Borí no Batuque, tradição de matriz africana que vivenciamos; no segundo analisamos certos aspectos dos Òrịsà e ofereceremos uma interpretação afroteológica do tema. No subtítulo seguinte, trataremos das relações interpessoais, como atos sexuais e relações românticas entre os vivenciadores. No último, tratamos brevemente de elementos da sexualidade e identidade de gênero.

As palavras em língua yorùbá que figuram neste trabalho estão escritos segundo a obra Uma abordagem moderna ao yorùbá, do linguista nigeriano Gideon Babalọlá Ìdòwú (2011).

\section{Liturgia como representação simbólica de um ato sexual}

Ao observarmos as liturgias das tradições de matriz africana é perfeitamente perceptível o simbolismo sexual que dela emerge. Isso é aparente nas principais liturgias como o bort ${ }^{6}$ e o assentamento de Òì̀sà que, a partir de nosso entendimento, figuram como representações simbólicas de um ato sexual. A teologia aqui é a de que o ato sexual é gerador de vida, logo representações simbólicas desse ato se apropriam de forma teológica de sua força que, então, será direcionada para a intenção do ritual.

\footnotetext{
5 Existe um debate no meio religioso e acadêmico a respeito da existência de uma "nagocracia" nos estudos das tradições de matriz africana. A "nagocracia" se refere a priorização dos estudos antropológicos, sociológicos ou etnográficos sobre a tradição de origem yorùbá (ou nagô), que gera em sua decorrência a ausência de estudos sobre outras tradições como as de origem ewe-fon (jeje) e bantu (Angola-Congo). No entanto, nossos estudos são em Teologia, na perspectiva da dinâmica civilizatória que perpassa todas as tradições, logo, o uso dos termos em língua yorùbá é meramente instrumental, uma convenção para melhor entendimento da questão sem reduzi-la a mera etnografia de um grupo. É perfeitamente possível que vivenciadores e pesquisadores de outras tradições possam refletir sobre o que vivenciam ou pesquisam explorando os conceitos aqui apresentados e fazendo a devida legbanêutica ou pambunjilanêutica.

6 A forma escrita deste termo está propositalmente em desacordo com a literatura antropológica atual, pois refletimos de modo diverso dos pesquisadores dessa área. A maioria - que se repetem sem se aprofundar no sentido da palavra - apresenta a escrita borí ou ainda eborí intentando criar uma palavra que expresse o que acreditam significar "alimento à cabeça" (ebo + ori $)$. No entanto, levantamos a dúvida em outros trabalhos sobre a veracidade deste termo e deste significado, sobretudo por causa de sua pronúncia: borí, pronúncia "bórí", é bem diferente da pronúncia corrente em todo o Brasil e na própria África: "bôrí". Isto pode indicar um significado diferente: $b i+o r i ́$, o nascer ou renascer da cabeça.
}

Periódicus, Salvador, n. 14, v.1, nov.2020-abr.2021 - Revista de estudos indisciplinares em gêneros e sexualidades Publicação periódica vinculada ao Núcleo de Pesquisa NuCuS, da Universidade Federal da Bahia - UFBA ISSN: 2358-0844 - Endereço: http://www.portalseer.ufba.br/index.php/revistaperiodicus 
No Batuque, tradição de matriz africana que vivenciamos e estudamos, podemos perceber essas nuances bem claramente. Na concepção afroteológica, o espaço sagrado onde se destinam os rituais imolatórios, que no Batuque é o pejí ou "quarto de Òrị̀ă" ou ainda "quarto de santo", é um verdadeiro útero mítico. Ali são realizados os ritos de borí e de assentamento de Òrișà.

Como já explicamos em outros trabalhos (SILVEIRA, 2013), o borí é um ritual iniciático de renascimento e cosmologização que garante a individuação da pessoa diante do coletivo em que ela está incluída, lhe construindo uma identidade; também a reintegra ao cosmo, laço este rompido com o corte do cordão umbilical no seu nascimento biológico; garante-lhe plena integração à comunidade, estabelecendo vínculos familiares tanto com as divindades como com os outros membros do grupo; e ainda mantém as estruturas sociais e hierárquicas dentro da comunidade ${ }^{7}$. (JAY, 1997)

É no centro do pejílútero que o neófito é colocado sentado no chão ${ }^{8}$. O chão representa a terra. Na maioria das tradições religiosas não patriarcais a terra é entendida como uma divindade feminina associada ao poder gerador de vida. Este entendimento se dá pela percepção material do crescimento das plantas que brotam do "ventre" da terra, de modo que o mundo natural e o espiritual estão sempre conectados. Para os yorùbá, o chão (Ilệ) não é uma divindade, mas sim a morada de Onílè, uma divindade feminina que ganhou de Olódùmarè, o Ser Supremo, o governo da terra.

De acordo com o itán (História Sagrada) que narra o acontecido, Onílẹ era a filha mais recatada e discreta de Olódùmarè. Não saía para nada. Um dia Olódùmarè resolveu dar aos Òrișà o governo da Terra e lhes chamou ao palácio, todos foram ricamente vestidos com elementos da natureza, exceto Onílẹ que cavou um buraco no chão e se cobriu com a terra. Sabiamente Olódùmarè deu aos Òrìșà o controle sobre cada um dos elementos da natureza dos quais eles mesmos haviam se vestido. Mas faltava ainda um dos reinos.

Era preciso dar a um dos filhos o governo da Terra, o mundo no qual os humanos viviam e onde produziam as comidas, bebidas e tudo o mais que deveriam ofertar aos orixás.

[Olódùmarè] Disse que dava a Terra a quem se vestia da própria Terra.

\footnotetext{
${ }^{7}$ Convém apontar que o Candomblé, de forma geral, não percebe o rito de Borí com toda a importância dada por nós. De alguma forma os sentidos cosmológicos desse importante rito foram, no Candomblé, obliterados por uma noção utilitarista que reduz sua importância a mera "oferenda à cabeça" como prática não iniciatória, logo não vinculativa, por isso indicada até mesmo a "clientes" - pessoas sem vínculo com o culto. É provável que isso se deu devido aos vários tipos de ritos considerados "Borî” no Candomblé. Pelo contrário, no Batuque, todo Borí requer sacralização de animais, o que gera os vínculos que apontamos no texto.

${ }^{8}$ No Batuque, "fazer chão" é uma expressão que significa cumprir o rito de bori ficando recluso por alguns dias no terreiro devendo dormir no chão. 
Quem seria?, perguntavam-se todos.

“Onilé”, respondeu Olodumare.

Ali estava Onilé, em sua roupa de terra.

Onilé deveria ser propiciada sempre para que o mundo dos humanos nunca fosse destruído.

Todos os orixás aclamaram Onilé.

Todos os humanos propiciaram a mãe Terra. (PRANDI, 2001, p. 410-415)

No Batuque, além de o neófito ficar sentado no chão, parte do àșorò ${ }^{9}$ é recolhido numa vasilha com água chamada de ẹko. Esta água é despachada no solo, seguindo alguns preceitos, alimentando a terra/Onílẹ. O chão está presente em todos os momentos do renascimento míticosimbólico do indivíduo. A saudação mais simbólica nas tradições de matriz africana consiste na pessoa se deitar ao solo, com o corpo estirado. Mais uma vez notamos aqui a importância do chão como símbolo feminino: mulheres deitam de lado e viram para o outro, sem encostar o ventre no chão, pois isso poderia ser entendido como se ela estivesse ofertando seu útero à Onílè. Já os homens deitam de bruços, com seu órgão genital encostando no chão, pois não há problema de oferecer o poder gerador masculino à Onílẹ. A mesma teologia é pensada no tocante à morte dos iniciados. Os corpos dos mortos são enterrados para que, assim, no "útero da terra", possam renascer no outro mundo. Já aludimos a isso em outro trabalho. (SILVEIRA, 2012)

Nas costas do neófito fica um sacerdote ou sacerdotisa que, a partir de então, será o seu padrinho ou madrinha. Ele ou ela carregam nas mãos uma vela acesa representando o fogo cósmico que transforma o universo; a chama que ilumina os caminhos. Ao mesmo tempo, a vela é um símbolo fálico e a chama em sua ponta pode nos apresentar um sentido mais sexual. O elemento fogo é sempre entendido como masculino, não é à toa que nas figuras de linguagem usamos o termo "fogo" como metáfora para o desejo sexual ${ }^{10}$. Com isso, podemos entender que

\footnotetext{
${ }^{9}$ Àsorò é o termo empregado no Batuque especificamente para o sangue dos animais sacralizados, nunca empregado para qualquer outro tipo de sangue (èjẹ). Existem duas versões sobre a origem da palavra "àșorò": a) Asșe + orò, significando "a força criadora que emana do rito"; b) Àwa + șe + orò, significando "nós fazemos o ritual". No Candomblé o termo empregado para o sangue das sacralizações é "èjẹe".

${ }^{10} \mathrm{Na}$ história do êxtase de Santa Tereza de Ávila, por exemplo, a santa foi penetrada por uma lança de ouro com a ponta de fogo conduzida por um serafim. Diz ela numa de suas obras: "Eu vi em sua mão uma longa lança de ouro e, na ponta, o que parecia ser uma pequena chama. Ele parecia para mim estar lançando-a por vezes no meu coração e perfurando minhas entranhas; quando ele a puxava de volta, parecia levá-las junto também, deixando-me inflamada com um grande amor de Deus. A dor era tão grande que me fazia gemer; e, apesar de ser tão avassaladora a doçura desta dor excessiva, não conseguia desejar que ela acabasse..." 
o papel mítico-simbólico da vela seja também garantir o apetite sexual, necessário para a continuidade da vida.

No colo do iniciante é depositado o ìgbá, um grande alguidar de barro, espécie de vasilha em que o fundo é muito mais estreito que a borda, mas também pode ser uma grande bacia de louça ágata; assim como o peji, todas as vasilhas, vasos, panelas e objetos cuja forma pode conter algo são representações simbólicas do útero que contêm a força e o poder da fertilidade feminina. Dentro dele é que ficam certos implementos que serão sacralizados.

O iniciante abraça o ìgbá de forma suave, com as mãos espalmadas para cima em posição de receptor. Na mão do sacerdote sacrificador - que no caso do Batuque é o próprio Bàbálórị̀à ou İyálórị̀à - está o ọbẹ, a faca ritual, utilizada exclusivamente para as imolações e sacralizações. O ọbe - assim como a espada (idà), a lança (okộ), o cajado (òpá), o cetro (ógọó) e o tambor (ìlù) - é um objeto fálico, cuja representação simbólica materializa o poder masculino de fecundidade.

Temos aqui dois elementos cruciais para a geração de vida: a faca/falo e o alguidar/útero. É a fusão de ambos que garante a geração de vida. E isso se dá pelo àșorò. O àṣorò, sangue que verte dos animais sacralizados, carrega a sua força vital e, ao mesmo tempo, é a representação simbólica do sêmen que fecunda.

No quadro que pintamos vemos o ọbẹ/falo que faz verter o èjệsêmen que fecunda o igbálútero que aguarda fértil de implementos que, então, se tornarão cheios de vida. O mesmo acontece com o iniciado que será entendido, a partir daí, como um renascido, uma nova pessoa, cheio de vida e plenamente humanizado. Assim como um nascituro está coberto com o sangue de sua mãe biológica, o neófito renasce coberto pelo sangue sagrado que assim se torna símbolo de seu (re)nascimento, como uma nova pessoa para a tradição; se inscreve num projeto de humanidade que o individualiza; se torna parte da comunidade por laços de consanguinidade mítica, descendência do Àsẹ; e se confirma a sua ascendência mítica com o Òrìsà ao qual foi consagrado.

Na sequência da liturgia o neófito, ainda dentro do pejí/útero, é erguido pelo Bàbálórị̀à ou İyálórìsà e pelo padrinho ou madrinha, um de cada lado, como se fossem os parteiros deste novo ser. Em seguida ele é conduzido até a porta do pejí/útero numa clara alusão a um parto, onde será entregue a um Òì̀sà manifestado que irá à sua frente, conduzindo seus passos, e outro às costas, lhe protegendo. Na teologia do borí fica claro o que esses Òrị̀à representam e o seu 
papel na vida do agora iniciado, algo que seguirá até o fim dos seus dias na Terra, um papel de condução e proteção constante pelos caminhos da vida.

Por alguns dias, o iniciado ficará recluso no salão, que no caso do Batuque é contíguo ao pejí, e será cuidado como se fosse uma criança recém-nascida. Ao fim do processo de reclusão haverá uma readaptação à vida normal. No Candomblé essa readaptação é encenada num pequeno rito em que são reensinadas ao neófito as práticas cotidianas em alusão ao crescimento da "criança". O rito se prolonga mesmo após a autorização de saída do iniciado do espaço material da comunidade com regras rígidas de controle alimentar, a proibição do consumo de bebidas alcoólicas e sexo (afinal crianças não fazem isso), além de evitar a visita a certos lugares e a exposição do orí (cabeça mítica e física) em certos horários. No Batuque, este período é nomeado de resguardo.

Ao final desse processo, o iniciado será considerado um com os Òrị̣à e com a comunidade. Será um ser humano completo. Convém salientar que a idade biológica das pessoas não tem validade no terreiro sob o ponto de vista hierárquico, o que conta é o tempo de iniciação, pois a nova vida extingue a velha. Os processos iniciáticos em África são concluídos quando o sacerdote responsável por uma iniciação lhe dá um novo nome. Este ritual, que também está presente no Candomblé, mas inexistente no Batuque, define um papel importante na inclusão do iniciado na família do Òrișà e no terreiro. Quando o iniciado recebe um novo nome, não pode ser mais chamado pelo anterior, pois, segundo Verger (1997), a vida anterior do iniciado está morta e a que conta é a que vive agora, abolindo todo o passado do indivíduo. Por isso o tempo de iniciação é o que conta nos terreiros, de forma que uma pessoa com 20 anos de idade e 15 de iniciação é considerada mais velha que uma de 50 anos de idade e 10 de iniciação.

\section{Sexo e os Òrìsà: análise afroteológica}

Assim como evidenciamos em algumas liturgias uma representação simbólica do sexo, também é possível verificar nos Òrișà as representações simbólicas das forças genitoras masculina e feminina. (SANTOS, 2002)

O ớgó de Èșù, o facão e a lança de Ògún, o machado de Șàngó, a flecha de Odẹlọsọoọsí, a vassoura de Ṣànpọ̀nná/Omọlu/Ọbalúwáyé e o cajado de Òșàálá, são representações simbólicas do poder fecundador masculino cujo aspecto geral é o falo.

Periódicus, Salvador, n. 14, v.1, nov.2020-abr.2021 - Revista de estudos indisciplinares em gêneros e sexualidades Publicação periódica vinculada ao Núcleo de Pesquisa NuCuS, da Universidade Federal da Bahia - UFBA ISSN: 2358-0844 - Endereço: http://www.portalseer.ufba.br/index.php/revistaperiodicus 
Das İyába ou Òrị̣à femininas temos no abano Abẹbẹ de Yánsàn, de Ộṣun e Yemojá e na ânfora de Qtin, a representação simbólica do poder de fertilidade feminino cujo aspecto geral é o útero, o órgão onde a vida é gerada.

Entre os Òrișà masculinos, a figura que se destaca é a de Òsàálá. Ele não é apenas o Pai da humanidade, mas também o Pai dos demais Òrị̀à. Esta característica mítica é de suma importância teológica, uma vez que Ele se torna, então, a manifestação simbólica da paternidade de Olódùmarè, ou seja, é o representante máximo do poder masculino de gerar vida que vem de Deus. Devido a sua ligação direta com as árvores e sua simbologia com o falo sempre ereto, Santos diz que Ele "representa coletiva e simbolicamente o poder ancestral masculino". (SANTOS, 2002, p. 77)

Mas a vida não pode ser gerada apenas pelo poder masculino e essa é a grande verdade teológica da existência. A sociedade africana é de certa forma patriarcal, mas, ao menos no período anterior à partilha do continente pelas potências europeias, as mulheres eram respeitadas e tinham poder e isonomia junto aos homens. Então podemos dizer que os homens e as mulheres compartilhavam o poder exercendo atividades e funções diferentes, mas essas atividades eram entendidas como complementares e não havia uma hierarquia entre elas. O machismo propõe que há uma hierarquia das atividades humanas, advogando uma superioridade das atividades ditas masculinas em detrimento das atividades ditas femininas. Antes da colonização europeia na África isto não existia.

O poder feminino é representado simbolicamente pelo abẹbẹ, um tipo de abano feito com couro de animais, em forma arredondada, com um cabo. Praticamente todas as İyába o carregam em mãos. Segundo Santos (2002), as entidades primordiais da maternidade são as poderosas İyámi Òṣòròngá, as Mães Ancestrais e, curiosamente, elas são conhecidas apenas coletivamente, não há nomes que as individualizem. Isto pode representar o espírito ético africano apontado por Moore como sendo uterocêntrico: 
[...] Isto faz com que a miséria material e moral sejam desconhecidas até os dias atuais. (MOORE, 2007, p. 150)

Vemos aqui, então, uma relação própria entre a simbologia do útero e a natureza da filosofia africana. O útero é o órgão onde a vida é gerada, protegida até o tempo certo para ganhar o mundo. Em um mesmo útero podem ser geradas muitas vidas e todas elas estarão ligadas entre si, neste sentido, como diz Moore, o Outro não é "totalmente outro". São os africanos nos ensinando muito antes de Lévinas a importância da alteridade para uma sociedade moral e eticamente sadia.

As İyá-mi Òșòròngá representam todo esse poder feminino que constrói miticamente um “comunitarismo filosófico sócio-ético" (GYEKYE, 2002, p. 298) que também está representado em suas descendentes vivas: as mulheres. A importância das mulheres está memoravelmente refletida num verso de Ifá colhido por Santos (2002, p. 110) em que a divindade da Criação, Òsàálá, exalta o poder de gestação das mulheres:

\section{E kúnlẹ o! E kúnlệf'obirin o!}

E obirin l'o bí wa, o k'awa tó d'enia

Ajoelhemo-nos diante da mulher!

A mulher nos pôs no mundo, permitindo nossa existência como seres humanos.

\section{Relações sexuais e românticas no terreiro}

Esta questão é bastante controversa nas tradições de matriz africana. Simplesmente não se fala sobre o que pode ou não pode fazer em termos de relações sexuais. Há, mais ou menos, um consenso permissivo com relação a isso, inclusive no tocante a relacionamentos extraconjugais.

Dag Øistein Endsjø afirma que as religiões, de forma geral, não são contra a prática do sexo. Apenas apontam para o jeito certo de se fazer, ou seja, propõem um controle dessa atividade.

Religiões de diferentes origens vêem o sexo como uma prática sagrada, pois gera vida, ou seja, serve aos propósitos divinos. Por isso, muitas vezes, na tentativa de corresponder ao que acreditam ser a vontade do Transcendente, estabelecem um controle frequentemente rigoroso sobre as práticas sexuais com a intenção de que ela aconteça do jeito correto. 
O mesmo não ocorre com as tradições de matriz africana, o controle é mínimo e geralmente responde ao senso comum da sociedade envolvente. Por exemplo: a família africana é muito estendida, tendo na poligamia uma prática comum; ainda que os terreiros reapresentem essa civilização, em grande parte, no tocante aos relacionamentos conjugais, procede-se à maneira da civilização ocidental profundamente arraigada em axiomas cristãos que permitem apenas a monogamia.

As comunidades tradicionais têm muita autonomia na criação de regras próprias, elas funcionam mais ou menos como um pequeno reino onde o Bàbálórị̀à ou a İyálórìsà detém o poder, não apenas como sumo sacerdote/sacerdotisa, mas também como rei ou rainha. Assim, estabelecem regras de acordo com seu entendimento moral sobre as coisas, seguindo sua própria vontade. Dentre essas regras está a questão das relações românticas e sexuais dentro do terreiro.

Na África há diferentes entendimentos a esse respeito. Ora há uma permissividade, ora há um rigor. Talvez os quinhentos anos de influência cristã e os mais de mil de influência islâmica na região de origem dos povos traficados para o Brasil possam responder o porquê de ser assim.

$\mathrm{Na}$ obra que trata sobre a história da Nigéria, o professor Michael Ademola Adesoji (1990) alega que, ainda hoje, neste país da África Ocidental, existem casamentos arranjados pelas famílias. Por lá, os homens se casam aos 30 anos e as mulheres aos 25, mas não sem antes investigar a família da pretendente para garantir que não há histórico de doenças como lepra e epilepsia. Por fim é consultado Ifá, o oráculo sagrado, para saber se este casamento é auspicioso para ambos. Caso positivo, o casamento é organizado.

\footnotetext{
Na noite em que a esposa se muda para a casa do marido, as duas famílias se reúnem. A primeira obrigação da moça na ocasião é pedir ao pai aconselhamento e bênção. Ajoelhada, a noiva ouve do pai os conselhos de como obedecer ao marido e à sua família. Isso feito, o pai lhe augura proteção divina e fecundidade. A filha geralmente chora no momento de se despedir da mãe e de lhe pedir a bênção. Os jovens da família da noiva acompanham-na até a casa do marido. Perto da nova casa, as mulheres casadas da família do marido dão presentes aos parentes da moça para que esta obtenha a permissão de entrar. (ADESOJI, 1990, p. 35)
}

Bem diferente ocorre com os hereros, um dos povos mais antigos do mundo, segundo estudiosos, e que vivem em parte da Namíbia, Botsuana e Angola. A poligamia é uma instituição entre os hereros, embora a sociedade seja patriarcal e os homens poderem ter quantas esposas 
desejar e puderem pagar o dote, a fidelidade não é um objetivo central em seus relacionamentos. Aqui, as mulheres, mesmo casadas, podem ter um ou dois namorados fixos e ainda se relacionar sexualmente de forma ocasional com quantos achar que deve, mas os filhos resultantes dessa permissividade conjugal serão sempre do marido.

Os casamentos também são arranjados, mas a noiva pode rejeitar o noivo, mesmo após o pagamento do dote, contudo, a paternidade dos filhos que ela tiver com outra pessoa será do noivo prometido. Há ainda troca de casais, por dias até, coisa que acontece somente entre grandes amigos; e também é comum o marido oferecer a esposa a um visitante como hospitalidade e boas-vindas em sua casa. Todos esses dados foram coletados por Sérgio Guerra e apresentados em seu documentário Hereros Angola. (LUZ, 2013)

Mas, nas comunidades tradicionais de terreiro gaúchas, alguns sacerdotes e sacerdotisas ainda defendem que a relação romântica ou sexual entre filhos/filhas de santo deve ser proibida por este se configurar como "incesto".

Beniste (2005) alega algo parecido que acontece nos Candomblés. Nesta tradição, é terminantemente proibido o casamento entre filhos de uma mesma İyálórị̀à. Contudo, é possível que um seja iniciado pela sacerdotisa e o outro por outra pessoa do mesmo terreiro, garantindo assim a permanência do casal na comunidade sem torná-los irmãos de santo. Em terreiros de Batuque que possuem dois sacerdotes isto também é realizado garantindo "que não se perca o critério do respeito e da seriedade”. (BENISTE, 2005, p. 89)

De acordo com Verger (1997), nos rituais de iniciação ao Òriṣà Ṣàngó, em Ọyọ́, a iniciadora recomenda que os iniciados a este Òrị̀à não se relacionem com os demais iniciados no culto, mas que podem tranquilamente com iniciados em outros cultos de Òrìșà.

De volta ao Rio Grande do Sul, vários terreiros aceitam que um casal já formado antes da iniciação faça parte do quadro de filhos da casa, mas não aqueles que se conhecem no próprio terreiro e desenvolvem sentimentos um pelo outro. A justificativa seria proteger o terreiro das "más línguas" que caluniariam a casa como sendo um lugar de encontros românticos/sexuais e não de práticas religiosas. Para outros, não há qualquer problema com relação a isto, desde que haja um mínimo de senso moral e comportamento apropriado nas interdependências da comunidade. 
Diferentemente do que ocorre nas casas sobre a questão dos relacionamentos dos filhos de santo entre si, em que varia o que é considerado aceitável ou não, o código de conduta não escrito que rege as comunidades tradicionais proíbe o relacionamento íntimo entre pais/mães e filhos/filhas de santo. Curiosamente não por ser considerado "incesto", que sugeriria as nomenclaturas, mas sim por ser considerado uma quebra da moral sacerdotal.

Como a sociedade envolvente é cristianocentrada, a própria sociedade apresenta o cristão católico como modelo de sacerdócio: um padre jamais deve se relacionar romântica ou sexualmente com seus fiéis. Este axioma acaba sendo apresentado como um modelo de como um sacerdote deve ser e mesmo que não haja o voto de celibato entre as tradições de matriz africana - sob um certo ponto de vista isto seria contrário a base cultural africana - o relacionamento romântico e sexual entre os iniciados e seus iniciadores é censurado.

Entrementes, este é um código que não penaliza. Apenas se diz que não se deve e ponto. É comum usar como argumento que isto prejudicaria a relação de poder que é estabelecida entre pais/mães de santo e seus filhos e também na relação entre os próprios filhos de santo. Tal posicionamento é baseado na experiência de outros, frequentemente não nominados. Sempre se cita a história de certo pai de santo que fez sexo com uma filha de santo e esta passou a achar que também mandava no terreiro e por isso os outros filhos de santo ficaram indignados e acabaram por abandonar a comunidade deixando o sacerdote sem nenhum filho de santo.

Essa história, que não se sabe ao certo se é fictícia ou real, expressa o próprio código de ética. É o exemplo que se apresenta como o legitimador de uma postura que, ao quebrar a ética, gera consequências terríveis, que para uma casa de Òrị̀à, representa o seu fỉm. Ainda que não haja qualquer elemento teológico que corrobore este posicionamento, essa história acaba por se tornar num verdadeiro itán, uma narrativa mitológica que passa uma mensagem moral. Apesar de toda essa orientação e cuidado, é um tanto comum surgirem "fofocas" de que fulano ou fulana se envolveu com o pai ou mãe de santo.

\section{Questões de gênero e sexualidade}

Nas tradições de matriz africana a questão de gênero é muito importante. Como já vimos antes, toda a teologia do rito iniciático passa pela premissa de que a força masculina unida à feminina gera vida. Isto pode dar a ideia de que há um rechaço da homossexualidade ou da transsexualidade, mas isto não está correto. A ideia de que o ser é força (TORRES, 
2015) nos proporciona a reflexão de que ao ser força, é independente da "casca" que se apresenta. Assim, homens e mulheres, mesmo trans, são meramente receptáculos da força masculina e da feminina e ainda além.

Segundo Alves (2012), na concepção afro-ontológica os humanos são seres bio-míticosociais, ou seja, se constitui subjetivamente a partir do bio, do mítico e do social, a um só tempo. De acordo com essa composição, possuímos características herdadas de nossos pais biológicos e também de nossos pais míticos, os Òrị̀à, de forma que é entendido no Brasil que os iniciados possuem uma origem mítica que também é dual, masculina e feminina. Todos esses aspectos se inscrevem de forma complementar, o que significa que as forças masculina e feminina, tanto biológica quanto mítica, se complementam na configuração da vida. Assim, temos dentro de cada um de nós as duas forças.

A cultura africana é muito sexualizada. Ao ler esta afirmativa o leitor pode se tomar de espanto e nos julgar, talvez por avaliar o seu conteúdo moral que, então, depreciaria a cultura africana. O que o leitor não se dá conta é que este "conteúdo moral" faz parte de um paradigma cristianocentrado, isto é, está de acordo com como o cristianismo vê o sexo. Endsjø afirma que o cristianismo não é contra o sexo, mas sim contra o jeito errado de se fazer o sexo. Apenas o coito no casamento é permitido e de forma alguma é permitida a sensualidade em qualquer aspecto do cotidiano, ou seja, a provocação ou a sexualidade aflorada e explícita é reprimida. Os cristãos devem conter seus impulsos sexuais e limitá-los ao convívio de seu quarto. Como vivemos numa sociedade cristianocentrada, ainda que não sejamos cristãos, reproduzimos esses valores naturalmente, assim nossa afirmativa vai lhes parecer depreciativa da cultura africana. Vários antropólogos do passado nos ensinam a nos desvestirmos de nossa cultura para entendermos a cultura do outro. E desvestirmos significa desnudarmos de tudo o que, para nós, parece ser correto ou errado e tentarmos entender a cultura do outro naquilo que ela se propõe a ser para aquele determinado povo. Clifford Geertz, um dos mais importantes antropólogos de meados do século XX, cita Wittgenstein:

Falamos... de algumas pessoas que são transparentes para nós. Todavia, é importante, no tocante a essa observação, que um ser humano possa ser um enigma completo para outro ser humano. Aprendemos isso quando chegamos a um país estranho, com tradições inteiramente estranhas e, o que é mais, mesmo que se tenha um domínio total do idioma do país. Nós não compreendemos o povo (e não por não compreender o que eles falam entre si). Não nos podemos situar entre eles. (GEERTZ, 2008, p. 10) 
Então lhes proponho a abandonar seus paradigmas para entender a afirmativa que retomo aqui: A cultura africana é muito sexualizada. Isto significa que a fusão das forças masculinas e femininas se dá através do sexo, seja no âmbito biológico ou mítico - pois até os Òrị̀à fazem sexo. Assim, podemos avaliar alguns aspectos da sexualidade e da atividade sexual e nos arriscamos a propor algo.

A heterossexualidade é diferente da heteronormatividade. A primeira é uma orientação sexual, enquanto a segunda é uma construção ideológica que precisamente propõe garantir poder e privilégios a quem possui o comportamento heterossexual, não apenas a questão biológica. Já a homossexualidade (e não homossexualismo, pois este o definiria como doença) é a orientação sexual para o mesmo sexo. Também há a bissexualidade, ou seja, são pessoas que possuem uma orientação sexual para ambos os sexos. De acordo com as tradições de matriz africana, nenhuma dessas orientações é impeditiva para o livre exercício da vivência afrorreligiosa, tampouco é determinante na ascensão dos graus hierárquicos numa comunidade tradicional. Não há qualquer preconceito com relação a isto.

Para as tradições de matriz africana as questões de gênero nunca se colocaram como fator decisivo nas relações de poder dentro da comunidade tradicional. Ali homens e mulheres têm funções diferentes porque o trabalho é teológico, assim como a própria diferença de gênero o é.

Para as tradições africanas absolutamente tudo é sagrado, inclusive o trabalho, logo o trabalho se constitui numa “economia teologal". (DUSSEL, 1997, p. 154) Um dos elementos de compreensão da humanidade a partir do sagrado é a questão do trabalho dentro das questões de gênero.

O falo é o símbolo representativo do poder sagrado masculino, enquanto que o útero é o símbolo do poder sagrado feminino, como já expomos. Desse modo, todos os objetos com formato fálico (tais como a faca, a espada, a lança, o tambor etc.) são sub-representações do falo, logo pertencem ao homem, pois potencializam e são potencializados por ele. Por isso as atividades masculinas estão mais voltadas para a guerra, a caça, a pesca etc.

Por outro lado, o símbolo representativo do poder sagrado feminino é o útero, por isso o trabalho feminino é aquele em que o seu poder gerador de vida pode ser direcionado, como no plantio e no preparo dos alimentos. A visão machista de mundo diz que o lugar da mulher é na cozinha porque no mundo ocidental o lugar mais importante é a sala, onde o homem lê seu jornal, assiste seus programas de TV ou se reúne com os amigos. A cozinha é sempre um local 
de labuta (e a cosmovisão ocidental é de que o trabalho é castigo divino), um lugar inferior onde as pessoas inferiores (mulheres) devem estar e se dedicar. Ao contrário, para as sociedades africanas a cozinha é um local sagrado sendo o principal da casa. A panela tem o formato uterino e é nela que a mulher exercerá o seu poder gerador de vida na transformação do alimento cru em cozido para garantir a vida de sua família.

Como a mulher é um ser inferior para a sociedade ocidental, é desprezada, a instituição da monogamia é para evitar que o homem (o ser superior) tenha contato com muitas delas. Já na cosmovisão africana a mulher é sagrada, por isso a poligamia garante que o homem esteja rodeado de sacralidade.

Entrementes, para a sociedade africana a mulher não é superior, mas possui equidade com o homem em direitos e deveres. As diferenças de função estão relacionadas exclusivamente à visão de sagrado que se tem sobre o papel de homens e de mulheres no mundo, visando sempre a complementaridade, simbiose e a continuidade da vida, que é o fator primordial da filosofia e da teologia africana.

Sobre a questão das práticas sexuais, como já expusemos antes, a monogamia é a instituição mais comum nos casamentos, bem diferente da prática africana da poligamia. Entrementes, tanto a monogamia quanto a poligamia são teologicamente fundamentadas, pois nos itán de Òșàálá esta divindade da Criação teria apenas uma esposa por toda a vida, Yemowo. Pelo contrário, as narrativas míticas de todas as demais divindades sempre as mostram mantendo relacionamentos múltiplos.

Ainda existem práticas modernas de relacionamento sexual. Estou falando dos casais liberais, swingers e o poliamor. Não há mais tempo para falarmos sobre essas práticas, mas mais à frente nos debruçaremos sobre elas e apresentaremos uma resposta teológica.

\section{Considerações finais}

Este trabalho efetivamente deu trabalho. O tempo nos foi um inimigo constante e impossível de contornar. A bibliografia específica é escassa e ficamos à mercê do que nos apresenta mais evidentemente.

Pudemos evidenciar que a conformação dos ritos africanos, sobretudo os praticados no Batuque do Rio Grande do Sul, estão mergulhados numa simbologia que emerge da atividade 
sexual. Pudemos perceber que os próprios Òrị̀à possuem relação com as forças masculina e feminina e que sua confluência garante a vida.

Também evidenciamos que as relações romântico/sexuais numa comunidade tradicional de terreiro são complexas e que existem interpretações variadas a respeito dessas relações; que o poder do sacerdote é supremo e definidor destes aspectos, sendo que a base epistemológica é a própria moral em que o sacerdote acredita, costumeiramente colonializados pelo cristianocentrismo, mesmo que isso contradiga aspectos típicos da maioria das culturas africanas.

Por fim pudemos apresentar, muito brevemente, que as relações de sexualidade, gênero ou práticas sexuais não interferem de forma alguma nas tradições de matriz africana. Não há tabus teológicos ou condições míticas para o impedimento.

As tradições de matriz africana são conhecidas pelo seu amplo acolhimento. $\mathrm{O}$ pensamento xenofílico e uterocêntrico típico das sociedades africanas são reproduzidos nas comunidades tradicionais de terreiro como elemento social intrínseco ao projeto de humanidade preconizado pela civilização africana e que, por isso, acolhe todo o tipo de sexualidade e gênero em seus quadros de filiação mítica. E isso é base para toda a composição de uma visão de mundo galgada no princípio ético do Ubuntu.

A afroteologia aqui se apresenta como um reomodo, um conceito que se apresenta ao experienciado, pois é a experiência que antecede os conceitos, de acordo com essa visão de mundo.

\section{Referências}

ADESOJI, M. A. Nigéria: história, costumes, cultura do povo iorubá e a origem dos seus orixás. [S. l.]: Edição do autor, 1990.

ALTUNA, R. R. A. Cultura tradicional banto. Luanda: Secretariado Arquidiocesano de Pastoral, 1985.

ALVES, M. C. Desde dentro: processos de produção de saúde em uma comunidade tradicional de terreiro de matriz africana. 2012. Tese (Doutorado em Psicologia Social) - Faculdade de Psicologia, Pontifícia Universidade Católica do Rio Grande do Sul, Porto Alegre, 2012.

BENISTE, J. As águas de Oxalá: (àwon omi Óșàlá). 3. ed. Rio de Janeiro: Bertrand Brasil, 2005.

DILTHEY, W. Os tipos de concepção do mundo e o seu desenvolvimento nos sistemas metafisicos. Tradução de Artur Morão. Lisboa: Edições 70, 1992. 
DUSSEL, E. Oito ensaios sobre cultura latino-americana e libertação. São Paulo: Paulinas, 1997.

ENDSJØ, D. Ø. Sexo \& religião: do baile de virgens ao sexo sagrado homossexual. Tradução de Leonardo Pinto. São Paulo: Geração Editorial, 2014.

FINCH III, C. S.; NASCIMENTO, E. L. Abordagem afrocentrada, história e evolução. In: NASCIMENTO, E. L. (org.). Afrocentricidade: uma abordagem inovadora. São Paulo: Selo Negro, 2009. p. 37-69.

GEERTZ, C. A interpretação das culturas. Rio de Janeiro: LTC, 2008

GRONDIN, J. Introdução à hermenêutica filosófica. Tradução de Benno Dischinger. São Leopoldo: Unisinos, 1999.

GYEKYE, K. Person and community in African thought. In: COETZEE, P. H.; ROUX, A. P. J. (org.). The African philosophy reader. Tradução de Thiago Augusto de Araújo Faria. New York: Routledge, 2002. p. 298. Disponível em: https://bit.ly/3pXCKmO. Acesso em: 16 mar. 2018.

İDÒWÙ, G. B. Uma abordagem moderna ao yorùbá (nagô): gramática, exercícios, minidicionário. 2. ed. Porto Alegre: Edição do Autor, 2011.

JAY, N. Com toda a tua descendência para sempre: sacrifício, religião e paternidade. São Paulo: Paulus, 1997.

LUZ, N. Um olhar brasileiro sobre os Hereros: em filme e exposição, fotógrafo apresenta a fascinante etnia africana. Por dentro da África, Rio de Janeiro, 8 maio 2013. Disponível em: https://bit.ly/36SVbRj. Acesso em: 24 jul. 2018.

MOORE, C. Racismo e sociedade: novas bases epistemológicas para entender o racismo. Belo Horizonte: Mazza, 2007.

OYĚWÙMÍ, O. The invention of women: making an African sense of western gender discourses. Minneapolis: University Of Minnesota Press, 1997.

PRANDI, R. Mitologia dos orixás. São Paulo: Companhia das Letras, 2001.

SANTOS, J. E. Os nagô e a morte: pàdé, àșẹșẹ e o culto égún na Bahia. 11. ed. Petrópolis: Vozes, 2002.

SILVEIRA, H. Gbobo ohun ti a bà se ni ayé l'a o kunlè rò ni Ọ̀run: processo escatológico no Batuque do Rio Grande do Sul. Identidade!, São Leopoldo, v. 17, n. 2, p. 247-258, 2012. Disponível em: https://bit.ly/2XmrbJi. Acesso em: 15 mar. 2018.

SILVEIRA, H. Afroteologia: elementos epistemológicos para se pensar numa teologia das religiões de matriz africana. In: CONGRESSO INTERNACIONAL DA SOTER, 26., 2013, Belo Horizonte. Anais [...]. Belo Horizonte: Soter, 2013. p. 1133-1143.

SILVEIRA, H. "Não somos filhos sem pais": história e teologia do Batuque do Rio Grande do Sul. 2014. Dissertação (Mestrado) - Faculdades EST, São Leopoldo, 2014.

TORRES, A. Filosofia africana e desenvolvimento: reflexões preliminares. Blog Filosofia Africana, Brasília, DF, 2015. Disponível em: https://bit.ly/3nNWecc. Acesso em: 16 mar. 2018.

VERGER, P. F. Orixás: deuses iorubás na África e Novo Mundo. Salvador: Corrupio, 1997. 